\title{
Life as a Cosmic Phenomenon: 2.The Panspermia Trajectory of Homo sapiens
}

\author{
N. Chandra Wickramasinghe ${ }^{1,3}$ and Gensuke Tokoro ${ }^{2,3}$ \\ ${ }^{1}$ Buckingham Centre for Astrobiology; University of Buckingham, Buckingham, UK \\ ${ }^{2}$ Hitotsubashi University, Institute of Innovation Research, Tokyo, Japan \\ 3 Institute for the Study of Panspermia and Astroeconomics, Gifu, Japan \\ *Corresponding author: Chandra WN, Buckingham Centre for Astrobiology, University of Buckingham, Buckingham, UK, Tel:44-777-838-9243; E-mail: \\ NCWick@gmail.com
}

Rec Date: June 13 2014; Acc Date: July 4 2014; Pub Date: July 62014

Copyright: (c) 2014 Wickramasinghe NC, et al. This is an open-access article distributed under the terms of the Creative Commons Attribution License, which permits unrestricted use, distribution, and reproduction in any medium, provided the original author and source are credited.

\begin{abstract}
We discuss the origin and evolution of Homo sapiens in a cosmic context, and in relation to the HoyleWickramasinghe theory of panspermia for which there is now overwhelming evidence. It is argued that the first bacteria (archea) incident on the Earth via the agency of comets 3.8-4 billion years ago continued at later times to be augmented by viral genes (DNA,RNA) from space that eventually led to the evolutionary patterns we see in present-day biology. We argue that the current evolutionary status of Homo sapiens as well as its future trajectory is circumscribed by evolutionary processes that were pre-determined on a cosmic scale - over vast distances and enormous spans of cosmic time. Based on this teleological hypothesis we postulate that two distinct classes of cosmic viruses (cosmic viral genes) are involved in accounting for the facts relating to the evolution of life.
\end{abstract}

Keywords: Panspermia; Cosmic origins of life; Biological evolution; Evolution of Homo sapiens; Viruses; Teleology

\section{Introduction}

In an earlier paper (Paper I) we referred to overwhelming evidence that supports the Hoyle-Wickramasinghe $(\mathrm{H}-\mathrm{W})$ theory of cometary panspermia including direct evidence for an ongoing ingress to Earth of fresh biological cells, and presumably also new viral genes that continually contributes to biological evolution. Much of the ongoing ingress of biomaterial is likely to be in the form of viruses that have recently been discovered to dominate the living biomass of the terrestrial oceans to the extent of $\sim 95 \%$. A single drop of ocean water is found to contain more than a million viral particles. Most of the viruses that have actually been sequenced and identified are phages viruses that affect bacteria - but a large component of uncharted viruses also exist.

Many years ago Hoyle and one of the present authors proposed that viruses of cosmic origin were intimately involved with the phenomenon of biological evolution as witnessed on the Earth [1,2]. It was proposed by these authors that the 2 emergence of new evolutionary traits, including new species, are connected with the incorporation and expression of cosmic viral genes. Ideas of horizontal gene transfer between organisms were not fully developed at this time and the H-W (Hoyle-Wickramasinghe) theory was based on a process that was still to be empirically verified. Many of the predictions based on the H-W theory of viral gene transfers have since been amply verified in a wide range of terrestrial settings [3-7].

An early criticism levelled against the $\mathrm{H}-\mathrm{W}$ theory was concerned with the apparent host specificity of viruses. How, it was asked, could a virus of extraterrestrial origin possess genetic sequences that match closely the genetic sequences in terrestrial life-forms? The answer, in the $\mathrm{H}-\mathrm{W}$ model, is that extraterrestrial viruses and terrestrial life forms must have co-evolved. In the present article we propose that a pre- evolution of the entire spectrum of past, present and future life occurred over vast spans of cosmic time, and over cosmic dimensions. Such an evolutionary legacy stored in the form of cosmic viruses is impressed, via the agency of comets, upon every habitable planet in the Universe. Evolved life on planets like the Earth can also disperse locally modified genes (DNA, RNA) back into the cosmos, making them available for evolution on other planets. This could happen through the mechanism of comet impacts as discussed by Napier [8] and by Wickramasinghe, Wickramasinghe and Napier [9].

\section{Virus properties}

Viruses are dependent for their replication on host cells, either prokaryotic or eukaryotic cells or even other viruses. Under interstellar and intergalactic conditions the persistence of viruses for almost indefinite lengths of time appears to be well guaranteed, compared to cellular forms of life $[10,11]$. This is because the survival of viruses does not depend on the availability of energy (food), and furthermore their nanometric sizes make them negligible targets for damage from cosmic rays. If, as we usually tend to think, viruses are always deleterious to higher life, resulting invariably in disease and death (negative aspects of viruses), the known properties of virus-cell synergy (positive aspect of viruses) would be mysterious. Even more mysterious is that host cells actually appear to invite viruses rather than reject them.

There are four stages in the process by which a virus multiplies itself within a cell, the prevention of any one of which will confer immunity on an evolved plant or animal.

1. The virus must possess an attachment protein and an attachment site to the host cell.

2. The interaction of the attachment protein with the cell wall must serve to strip other viral proteins away from the genetic material of the virus, which must then be afforded naked ingress into the host cell. 
3. The viral genetic material must have the ability to insert, transfer and overwrite the normal genetic programme of the cell, and

4. After multiplying itself within the cell the vast numbers of new viral particles must be able to gain egress from the cell in order to enter other cells.

With so many opportunities to frustrate the entry of viruses it is baffling that evolved life-forms have not availed themselves of these opportunities. Why have host cells, over their long evolution, failed to develop genetically so as to prevent the overwriting of viruses in general? Logically such a possibility must exist since the much greater quantity of information present in the genetic material of the host must be able to overcome the comparatively trivial amount of information of the virus. Yet such a defence has not evolved, and it is interesting to ponder the question - why? And why, in our modern scientific culture, have we established the illusion that viruses are always the villains?

Evidence for the oldest bacterial life on Earth in the form of a carbon isotope anomaly exists within sedimentary rocks dated at 3.83-4 billion years ago during the Hadean epoch [12]. At this time the Earth was relentlessly bombarded by comets that are now known to have brought water to form the Earth's oceans. The most reasonable inference is that the impacting comets also delivered the first life to our planet in the form of bacteria. The first cometary bacteria can be likened to a box (flesh) designed to house the continuing entry of cosmic viral genes (brain).

Complex life-forms have increased the number of their genes from 500 to some 25,000 over a period of 4 billion years. Where one might wonder do new genes come from? Particularly, the genes that led over geological timescales to huge surges of new developments in biology new domains, kingdoms, divisions, classes, orders, families, genus and species. A process of gene addition does in fact exist and is now welldocumented [3].

Viruses have the well-proven ability in some cases of not destroying the host cells but of developing a symbiotic relation with them. In some cases the viral genetic material actually adds to the host genetic material contributing several new genes in one fell swoop. If the evolution of terrestrial life-forms depends for its source of new genes on this well-attested process, then we can see why a rigorous immunity to viral attack is not possible. Any life form that developed such immunity will be unable to evolve.

\section{Information Content of Life}

One of the early arguments used for asserting a cosmic origin of life was its vast information content that would be difficult to understand on the basis of the canonical primordial soup theory $[2,13,14]$. The simplest autonomous bacterium typified by Mycoplamsa genitalium has about 500 genes, whilst a human being has 22,000 - 25,000 genes coding for useful enzymes. Not all the sites of a few hundred amino acid long enzyme chain needs to be correctly filled, however. For a single enzyme $\sim 10$ sites are required to be correctly filled by one of a set of $\sim 20$ biological amino acids. On this assumption the probability of a minimal set of enzymes arising from random shuffling of amino acids can be calculated. The result is $~ 1$ in 106500 for Mycoplasma genitalium. The overwhelmingly vast information content implied here leaves no option but to assert a cosmic origin of life $[2,14]$.

The conventional point of view is that the formidable information hurdle for forming the simplest bacterium was somehow overcome through a process of chemical evolution in a primordial soup on the Earth; and that for higher life, including humans, the even greater information hurdle was overcome through a process of mutations and natural selection. No numerical justification of the process has been presented, however. The idea of such processes leading to the required levels of biological information is likely to be a delusion [14].

Since random shuffling of constituent molecules (eg amino acids) cannot achieve the desired result for a set of biological enzymes one might think of exploring the hypothesis that there is some hidden property of matter, at say a nuclear level, that makes organic matter inevitably find the crucial arrangements for life - eg in a canonical primordial soup. If this were true one could argue that such a principle would have been discovered in one of the many origin-of-life experiments that have been carried out to date $[15,16]$.

The volume of a typical laboratory flask is less than the volume of all the oceans of the Earth by a factor of only 1021, and a typical timescale for a laboratory experiment (of, say, a day) is less than a geological epoch $109 \mathrm{yr}$, by a similar factor. This would mean that a perceptible trend towards the correct arrangements of the molecules for life must be detectable in the laboratory context, and needless to say this has not been achieved [16].

The alternate viewpoint that viral genes are continually added to genomes of evolving life-forms leaves the role of neo-Darwinian evolution occupying a less important role as a kind of fine-tuning, rather than as the main driving force [3]. Major evolutionary traits in the development of complex life are all externally derived, and evolution essentially driven from outside. If this is so the overall impression will be of a pre-programming in the higher levels of development in biology. The mechanism is that the relevant viral genes that were transported to Earth had evolved over vast timescales and in innumerable locations and suddenly came to be expressed locally on the Earth. The evolution of the eye may be seen as one example of this type, and even some highly complex, and less definable manifestations of gene expression in our own immediate line of descent in hominid evolution bear the signs of "pre-programming" or pre-evolution as pointed out by S. Ohno [17] who wrote thus:

"Did the genome of our cave-dwelling predecessor contain a set or set of genes which enabled modern man to compose music of infinite complexity and write novels with profound meaning? One is compelled to give an affirmative answer......It looks as though the early Homo was already provided with the intellectual potential which was in great excess of what was needed to cope with the environment of his time....."

It can be speculated, consistent with the $\mathrm{H}-\mathrm{W}$ theory, that the relevant genes for all such processes, including the musical and intellectual development in humans discussed by Ohno, evolved in a cosmic context and involved dispersal and exchange of viral genes across billions of light years. We can argue that Darwinian evolution occurred not on a single planet like Earth but over innumerable habitats in the grandest possible cosmic setting. We saw in Paper I that evidence from the examination of meteoroids and other astronomical data supports this point of view. The huge numbers of habitable planets that have recently been detected and the estimated mean distance of such planets being only a few light-years, imply that panspermia must be regarded as inevitable [18-20]. 


\section{Guaguin's Cosmic Questions}

From studies of aquatic environments it is estimated that about $10^{31}$ viruses are always in our midst [21], and the bulk of this grand total is likely to have fallen from the skies. Such viruses can have played three well-attested roles throughout our evolutionary history. They could cull us through the mechanism of disease (viral multiplication); they could protect us as in the role of placental syncytium, a virus-caused cellular membrane, that protects a fertilised egg (non-self) from being attacked by the immune system; or they could merge with our DNA (endogenisation), endowing it with evolutionary potential. If all such viruses are of cosmic origin, as we argue, it is not surprising that ingrained in every human being there is an instinctive feeling of a deep connection with some major aspect of the Universe. Early man gave expression to this feeling by inventing pantheons of gods that mostly resided in the sky; and later religions inherited similar traditions that continue to the present day.

Artists through the ages also depicted a similar cosmic connection, as for instance in the famous painting in 1897 by Paul Guaguin with the title: "Where do we come from? What are we? Where are we going?" As clearly seen in the reproduction in Figure 1, the reverential gaze upwards to the sky tells the whole story.

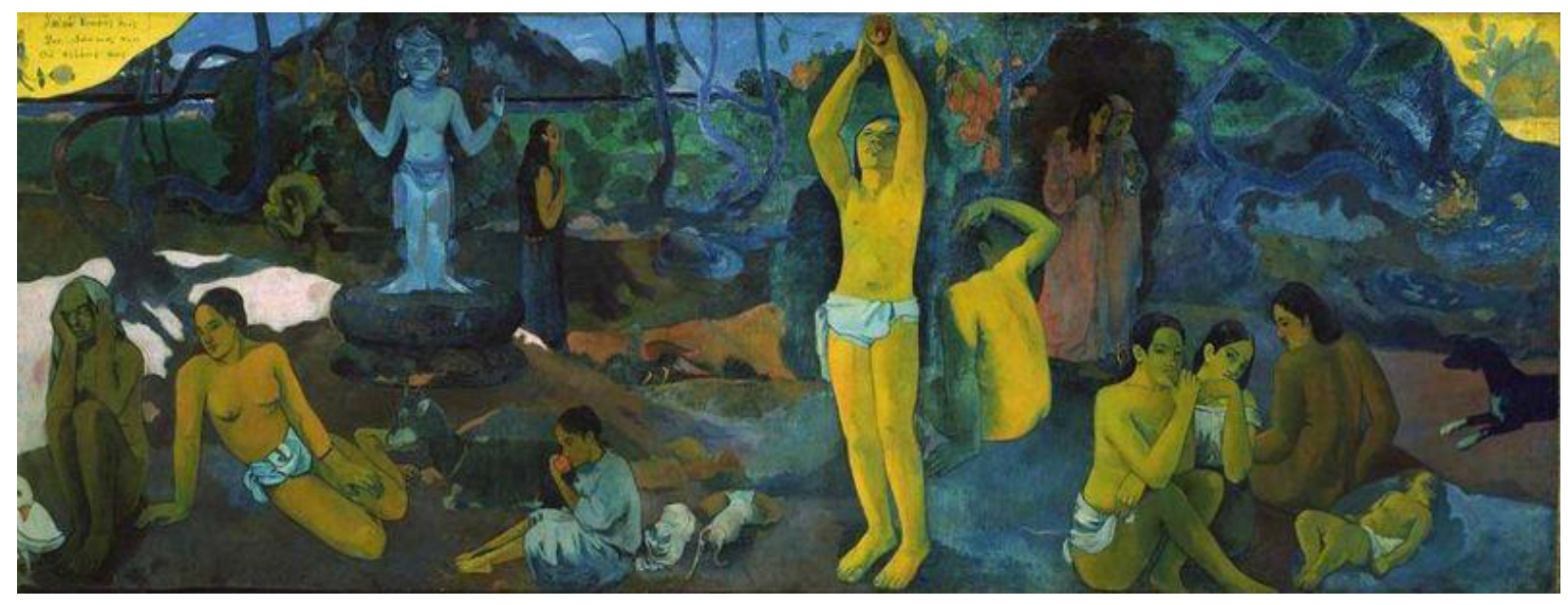

Figure 1: Guaguin's painting 1897: "Where do we come from? What are we? Where are we going?"

As for the answers to Guaguin's questions, the first "Where do we come from?" is already answered. We (our DNA) came from space in the form of bacteria and viruses, cosmic viruses that evolved an almost infinite range of evolutionary outcomes over aeons of time. The answer to Guaguin's second question - what are we? - is thus also, at least partially, 7 answered by virtue of developments in biology that have taken place after the dawn of the millennium [22]. In 1990 the US Department of Energy together with the National Institute of Health initiated the project of mapping the human genome. This was carried out independently by 20 institutions in the US, Britain, France, Germany, China and Japan over the next decade, and by 2003 the entire human genome was sequenced and mapped. This monumental feat of technological achievement was announced to the world as soon as the first draft genome sequence became available in the year 2000 jointly by the US President Clinton and British Prime Minister Tony Blair.

With the human genome thus sequenced our cosmic ancestry was essentially laid bare [23]. To our great surprise we have discovered that much of our genetic inheritance may be comprised of DNA actually delivered by viruses. At least $43 \%$ of the entire human genome may be traced directly to viruses and their closely related products. This estimate is based on the likely hypothesis that $34 \%$ of the human genome which constitute LINEs (Long Interspersed Nuclear Elements) (21\%), and SINEs (Short Interspersed Nucluear Elements) (13\%), which are retroviral derived and controlled, and HERVs (Human Endogenous Retroviruses) and LTRs (Long Terminal Repeats) (9\%) $[5,22]$.
We can now answer Guaguin's second question with confidence. We are essentially a complex of cosmic viruses; our evolution in every significant respect was directed by the ongoing incidence of cosmic viruses. In the fullness of time, long before the Sun exhausts its hydrogen fuel and becomes a red giant, some part of our augmented and reshuffled genomes will return to space to influence the evolution of life elsewhere in distant cosmic habitats. "Seeds" carrying our Earthly genetic heritage will at last come to be sown on other planets. Guaguin's third question "Where are we going to?" has the answer "We are going back into space - back into the cosmos where we came from."

\section{The Predestiny of Profligacy}

From the entire spectrum of life forms presently on Earth a clear division exists in regard to their utilisation and expenditure of energy. The vast majority of species from the three domains of life, archaea, bacteria, eukarya, may be described as "survival limited" implying that only such energy is consumed as is needed to maintain life. A trivial minority (ourselves, Homo sapiens), latecomers on the scene, the last mammals, merit the description 8 of "energy profligate", those who are obstinately determined to expend the non-renewable energy capital of the planet, with little regard for conservation or ecology. This is easily seen in the fact that the average energy consumption by modern humans is $47,400 \mathrm{kcal} /$ day per individual which is some 24 times more than the bare survival energy consumption rate of $\sim 2000 \mathrm{kcal} /$ day (Source: IEA, Energy Balances of OECD Countries; United Nation White Paper on Population, 2011). In the evolution of hominids that 
led to the emergence of Homo sapiens some 200,000 years ago, this trait became manifest only in very recent times.

Let us begin by surveying the development of our ancestral line as it has been revealed by modern gene sequencing. First of all we should note that our phylogenetic links have now been traced back to fungi that emerged some $700-1000$ million years ago [24,25]. At this early stage our distant ancestors, along with other life forms, expended only the barest minimum energy and resources needed for maintenance and reproduction (survival equivalent). About 7 million years ago our ancestral evolutionary line diverged from chimpanzees living on trees, and started to walk upright on two legs (eg Sahelanthropus, Ardipithecus, Australopithecus) with the ability to use his hands to make tools. Not long afterwards, 2.5 million years ago, Homo habilis emerged, and about 1.0-1.5 million years ago Homo erectus exploited the use of fire, and this led eventually to the exploitation of energy sources based on wood, coal, oil, gas and ultimately uranium and plutonium in the present day. Until this time we had been content to survive on the minimum $2000 \mathrm{kcal} /$ day ration or less of energy, living along with all other life forms in perfect harmony with our planet.

A crucial turning point in the fortunes of Earth may have occurred about 50,000 years ago when Homo sapiens suddenly acquired a set of genes, including the FOXP2 gene [26-29], that enabled him to use words and develop language. This crucial development enabled us to transmit ideas, engage in discourses, and ultimately to discover and accumulate knowledge and experience leading to science and modern technology. From this moment onwards Homo sapiens abandoned the "survival constrained" way of life and began to consume more and more energy - vastly more than was required for basic maintenance.

In the millennia that followed, societies, kingdoms, and nationstates came into being along with economic systems that basically determined the distribution of wealth. All these 9 developments apparently betrayed the natural order of the living world on our planet Earth. "Tradition" was the rule of survival in the most primitive hunter-gatherer societies, the head of the family determining the distribution of wealth (the catch). The rule of survival then shifted to "Command" in agricultural societies, where the head of the society, the King, decides on the distribution of the harvest. This order of things prevailed as long as centralised control provided the cohesive force necessary to maintain a stable society. The fall of the Roman Empire in $476 \mathrm{AD}$ may illustrate the result of decentralising such a single hierarchical system into a multiplicity of hierarchical units on a global scale. Thereafter "Command" was finally predominantly replaced by "Laissez Faire" - "Free for all" which still dominates most capitalist economies of the present day [30].

Based on the ideas we have discussed above, it is tempting to speculate on the existence of two distinct classes of cosmic viruses cosmic viral genes - which resulted in two distinct classes of life on the Earth:

1. Life affinity to Earth viruses (Le RNA/DNA class) where viruses promote an ergonomic and ecological balance of a host planet. Such viruses are in the majority and have dominated the development of life on the Earth except for the last 50,000-100,000 years.

2. Life affinity to Universe viruses (Lu RNA/DNA class) where viruses execute a cosmically determined imperative to advance their hosts spiritually, intellectually and technologically, and in so doing promote the expenditure of the energy resources of the host planet.
Assigning cosmic intent or pre-destiny to the two viral classes, we could hypothesise that the aim of Le is to seek out Earth-like planets and reside for as long as possible on such planets. The aim of $\mathrm{Lu}$, on the other hand, is to stay for as short a time as possible on a planet, communicate high levels of cosmic intelligence to an evolving line (such as the hominids) and on a cosmic scale of time "quickly" return to space.

An Lu-imbued life form might be programmed by its constituent viruses to reject or disown its own cosmic origins, and this could explain the dilemma discussed in Paper I [31]. When we finally come to terms with our cosmic origins it may be time to embark on a final voyage - back to space! Comets and asteroids 10 have struck the Earth sporadically causing a succession of episodes of extinctions of species. One such event happened 65 million years ago that led to the extinction of the dinosaurs and may well have shot Le DNA/RNA back into space. We cannot predict when the next comet or asteroid impact will take place, but when it does (perhaps 10,000 years hence!), our genes, enhanced with Lu DNA/RNA, will find their way back into space.

\section{Teleology and Science}

From their manifest properties it could be said that the primary objective of viruses is replication, which seems to be their ultimate "cosmic will". Of course H. sapiens do not want to admit that. Such an implied attribution of purpose or predestiny would diminish his/her own self-determination as well as the role of "cause" for every phenomenon in the natural world. From what we have discussed above it would appear that the nature of living forms on the Earth is indeed predetermined to a large extent by what appear to be intrinsic properties of the Universe - the Lu viruses in particular. Plato and Aristotle shared the view that the natural world is similarly endowed with intrinsic values and final causes, which it would be our duty to discover. This defines the philosophy of Teleology in which the present state of the world is determined by conditions that would prevail at a future time. Science has generally shunned such teleological ideas on the grounds that they are beyond the bounds of direct experimental verification. But that is not to say that it is wrong.

\section{References}

1. Hoyle F, Wickramasinghe C (1981) Evolution from Space. J.M. Dent, London.

2. Hoyle F, Wickramasinghe NC (1982) Proofs that Life is Cosmic. Mem. Inst. Fund. Studies Sri Lanka.

3. Wickramasinghe NC (2012) DNA sequencing and predictions of the cosmic theory of life. Astrophys Space Sci 343: 1-5.

4. De Groot NG, Otting N, Doxiadis GGM, Jonathan LH, Pascal G, et al. (2002) Evidence for an ancient selective sweep in the MHC class I gene repertoire of chimpanzees, PNAS 99: 11748-11753.

5. Horie M, Honda T, Suzuki Y, Tatsuo O, John MC, et al. (2010) Endogenous non-retroviral RNA virus elements in mammalian genomes. Nature 463: 84-87.

6. Ryan FP (2004) Human endogenous retroviruses in health and disease: a symbiotic perspective. J R Soc Med 97: 560-565.

7. Ryan F (2009) Virolution. Collins, Sheffield, UK.

8. Napier WM (2004) A mechanism for interstellar panspermia. Mon. Not.R. astr. Soc. 348: 46-51.

9. Wickramasinghe J, Wickramasinghe NC, Napier WM (2010) Comets and the Origin of Life. World Scientific Press, Singapore.

10. Wesson PS (2011) Necropanspermia. The Observatory 131: 63-66 
Citation: Wickramasinghe NC, Tokoro G (2014) Life as a Cosmic Phenomenon: 2.The Panspermia Trajectory of Homo sapiens. Astrobiol Outreach 2: 115. doi:10.4172/2332-2519.1000115

Page 5 of 5

11. Wickramasinghe C (2011) Viva Panspermia. The Observatory 131: $130-134$.

12. Mojzsis SJ, Arrhenius G, McKeegan KD, Harrison TM, Nutman AP (1996) Evidence for life on Earth before 3,800 million years ago. Nature 384: 55-59.

13. Oparin AI (1953) The Origin of Life (trans. S. Marguli).Dover, England.

14. Hoyle F, Wickramasinghe NC (2000) Astronomical Origins of Life: Steps towards Panspermia. Kluwer Academic Press, Dordrecht.

15. Miller SL, Urey HC (1959) Organic Compound Synthes on the Primitive Earth. Science 130: 245-251.

16. Deamer D (2011) First Life. Univ. of California Press, USA.

17. Ohno S (1970) Evolution by gene duplication.

18. Mayor M, Queloz D (1995) A Jupiter-mass companion to a solar-type star. Nature 378: 355-359.

19. Kopparapu R (2013) A revised estimate of the occurrence rate of terrestrial planets in the habitable zones around kepler $\mathrm{m}$-dwarfs.

20. Smith W, Wickramasinghe NC (2014) Hypothesis.

21. Bergh O (1989) High abundance of viruses found in aquatic environments. Nature 340: 467-468.

22. Villarreal LP (2004) Can Viruses Make Us Human?. Proc American Phil Soc 148: 296-323.

23. Venter JCJ, Adams MD, Myers EW, Li PW, Mural RJ, et al. (2001) The sequence of the human genome. Science 291: 1304-1351.
24. Lucking R, Huhndorf S, Pfister D, Plata ER, Lumbsch HT (2009) Fungi evolved right on track. Mycologia 101: 810-822.

25. Love GD, Emmanuelle G, Charlotte S, David AF, John PG, et al. (2009) Fossil record of the appearance of Demospongiae during the Cryogenic period. Nature 457: 718-721.

26. Hurst JA, Baraitser M, Auger E, Graham F, Norell S (1990) An extended family with a dominantly inherited speech disorder. Dev Med Child Neurol 32: 352-355.

27. Fisher SE, Vargha-Khadem F, Watkins KE, Monaco AP, Pembrey ME, et al. (1998) Localisation of a gene implicated in a severe speech and language disorder. Nat Genet 18: 168-170.

28. Vargha-Khadem F, Gadian DG, Copp A, Mishkin M (2005) FOXP2 and the neuroanatomy of speech and language. Nat Rev Neurosci 6: 131-138.

29. Lai CS, Fisher SE, Hurst JA, Fox M, Jeremiah S, et al. (2000) The SPCH1 region on human $7 \mathrm{q} 31$ : genomic characterization of the critical interval and localization of translocations associated with speech and language disorder. Am J Hum Genet 67: 357-368.

30. Heilbroner RL (1992) Twenty-first Century Capitalism. House of Anansi Press, Canada.

31. Wickramasinghe NC, Tokoro G (2014) Life as a cosmic phenomenon: 1. The socio-economic control of a scientific paradigm. 